\title{
Assessment of the Effects of Atmospheric Oil Pollution in Post War Kuwait
}

\section{Capt M D Coombe}

MB, BS, RAMC

Regimental Medical Officer

39th Regiment Royal Artillery, British Forces Post Office 16

Maj S F Drysdale

MRCS, LRCP, RAMC

SUMMARY: A prospective study was undertaken to assess and monitor the effects of oil pollution in soldiers exposed in Kuwait in 1991 after Op Granby. One hundred and twenty five soliders were monitored over a five month period by measurement of Forced Expiratory Volume (in one second) $\left(\mathrm{FEV}_{1}\right)$ and Forced Vital Capacity (FVC). Although no demonstrable changes were observed, this study has gone some way to filling the gap in research in this environmentally sensitive field.

\section{Introduction}

The Gulf War in 1991 left Kuwait destroyed. As part of an international clearance effort, a squadron of British bomb disposal engineers were deployed and remained in station for five months.

The extensive destruction of oil wells resulted in vast areas of atmospheric pollution which the international news coverage made plain. "Night and day blended into one as no light could penetrate the oil cloud."

This study was undertaken to assess the possible ill effect of the pollution and where necessary withdraw any affected individuals.

\section{Method}

One hundred and twenty five soldiers were deployed to Kuwait City consisting of the main body of the Royal Engineers bomb disposal unit. All personnel were between the ages of 18 and 44 with a mean age of 26 and were all deemed medically fit (P2 FE).

The study was of a prospective cohort design.

Before leaving UK all subjects completed a health questionnaire and had their respiratory function measured using an electronic compact vitalograph. The results were the best of 3 manoeuvres and are shown in Table 1.

\section{Table 1}

Respiratory Function Parameters Recorded

\begin{tabular}{lll}
\hline FVC & FEF 25-75\% & FEF 50\% \\
FEV 1 & PEF & FEF 75\% \\
FEV 1/FVC & FEF 75-85\% & FMFT \\
\hline
\end{tabular}

From June to October 1991 in Kuwait, individuals had the measurements repeated every fortnight. Anyone showing marked deterioration greater than $15 \%$ was to be fully examined and if necessary subjected to further investigation. Just before returning to UK the subjects repeated a similar but shorter questionnaire.
Table 2

Monthly Mean Concentration of Gases as PPM or PPB

\begin{tabular}{lllllllll}
\hline \multicolumn{4}{c}{ May 89 } & \multicolumn{4}{c}{ May 91 } \\
\hline Gases & & Mean & Max & $\begin{array}{c}\text { \% Ex } \\
\text { Limit }\end{array}$ & Mean & Max & $\begin{array}{l}\text { \% Ex } \\
\text { Limit }\end{array}$ \\
\hline $\mathrm{TS}$ & (PPB) & 2.372 & 91.000 & - & 2.206 & 22.000 & - & \\
$\mathrm{H} 2 \mathrm{~S}$ & (PPB) & 0.370 & 89.000 & 1.2 & 0.048 & 7.000 & 0.0 & \\
$\mathrm{SO} 2$ & (PPB) & 2.005 & 5.000 & 1.2 & 2.123 & 20.000 & 0.0 \\
$\mathrm{THC}$ & (PPM) & 2.200 & 9.350 & - & 6.920 & 20.750 & - \\
$\mathrm{NCH} 4$ & (PPM) & 0.366 & 7.090 & 53.4 & 1.176 & 10.600 & 87.7 \\
$\mathrm{NOX}$ & (PPB) & 42.295 & 628.000 & - & 18.127 & 424.000 & - \\
$\mathrm{NO}$ & (PPB) & 17.524 & 606.000 & 6.6 & 5.621 & 360.000 & 3.1 \\
$\mathrm{~N}_{2} \mathrm{O}$ & (PPB) & 24.824 & 186.000 & 6.7 & 12.520 & 74.000 & 1.6 \\
$\mathrm{CO}$ & (PPM) & 0.842 & 9.840 & 0.2 & 0.254 & 7.900 & 0.0 \\
$\mathrm{O} 3$ & (PPM) & 0.006 & 0.079 & 0.0 & 0.001 & 0.013 & 0.0 \\
$\mathrm{NH} 3$ & (PPM) & - & - & - & - & - & - \\
\hline
\end{tabular}

The atmospheric levels of pollution of gases (shown in Table 2) and particulate matter (PM10) were measured by Kuwaiti environmental monitoring stations and the results presented to the authors through US colleagues at CDC Atlanta. Individual exposure was crudely quantified by documenting the areas of Kuwait in which individuals had been working. Wind direction and speed made the different locations vary in pollution levels.

Forced Expiratory Flow $25-75 \%$ (the middle $50 \%$ of $\mathrm{FEV}_{1}$ ) was chosen as the most sensitive available measure of early small airway changes (1). The results were analysed as paired sample using the pre-deployment measurement and the last measurement before departure from Kuwait. The effects of previous symptoms or disease and cigarette smoking reported prior to deployment were investigated separately. Associations between reported respiratory symptoms, smoking and exposure to the pollution during the tour were sought separately.

Additionally the possibility of a synergistic effect of smoking and exposure was investigated. One and two way analysis of variants was used for this. 
Table 3

Mean Difference and Standard Error in FEV 25-75\% before and after Exposure by History of Smoking

\begin{tabular}{lrccc}
\hline $\begin{array}{c}\text { Amount } \\
\text { Smoked }\end{array}$ & n & $\begin{array}{c}\text { Mean } \\
\text { Difference }\end{array}$ & $\begin{array}{c}\text { Standard } \\
\text { Deviation }\end{array}$ & $\begin{array}{c}\text { Standard } \\
\text { Error }\end{array}$ \\
\hline Non Smoker & 45 & 0.08 & 0.65 & 0.1 \\
Ex Smoker & 11 & 0.22 & 0.72 & 0.22 \\
0-9/day & 10 & 0.76 & 1.57 & 0.5 \\
10-19/day & 32 & 0.04 & 0.83 & 0.15 \\
20/day & 5 & -0.13 & 0.84 & 0.38 \\
\hline
\end{tabular}

\section{Results}

1. No subject was withdrawn from Kuwait because of deteriorating lung function.

2. One hundred and twenty five subjects completed the first questionnaire and provided a predeployment reading of FEF $25-75 \%$. Of these, 100 completed the second questionnaire and a post deployment reading, although in total 109 provided this post tour measurement. Fourteen subjects were removed prematurely from Kuwait for other reasons and 6 did not complete the second questionnaire.

3. When subjects were stratified according to either smoking history prior to deployment or by amounts smoked during the tour, no significant differences between these groups were detected. In neither case was there evidence of a trend in the differences across the different smoking groups. Table 3 shows the results for smoking history prior to departure.

4. A degree of exposure to smoke as reported subjectively did not appear to have any effect on respiratory function (Table 4). When the combined effect of exposure to the smoke was examined, no differences were detected and there was no notable synergistic effect (Table 5).

5. Neither respiratory symptoms prior to deployment nor symptoms reported during the tour resulted in a significant difference in the measurement.

\section{Table 4}

Mean Difference and Standard Error in FEV 25-75\% before and after Exposure by History of Wheeze and Symptoms of Wheeze

\begin{tabular}{lccccc}
\hline \multicolumn{2}{c}{ Category } & n & $\begin{array}{c}\text { Mean } \\
\text { Difference }\end{array}$ & $\begin{array}{c}\text { Standard } \\
\text { Deviation }\end{array}$ & $\begin{array}{c}\text { Standard } \\
\text { Error }\end{array}$ \\
\hline Wheeze & Yes & 92 & 0.14 & 0.87 & 0.09 \\
History & No & 11 & 0.12 & 0.94 & 0.28 \\
\hline Wheeze & Yes & 74 & 0.19 & 0.93 & 0.11 \\
Symptoms No & 29 & 0.01 & 0.70 & 0.13 \\
\hline
\end{tabular}

Mean Difference and Standard Error in FEV 25-75吿 before and after Exposure by Level of exposure to Heaqy Smoke

\begin{tabular}{|c|c|c|c|c|}
\hline $\begin{array}{l}\text { Exposure } \\
\text { Category }\end{array}$ & $\mathbf{n}$ & $\begin{array}{c}\text { Mean } \\
\text { Difference }\end{array}$ & $\begin{array}{l}\text { Standard } \\
\text { Deviation }\end{array}$ & $\begin{array}{c}\text { Standared } \\
\text { Erros? }\end{array}$ \\
\hline Never exposed & 29 & 0.20 & 1.18 & $0.22 \overline{\mathrm{C}}$ \\
\hline$>1-2$ a week & 50 & 0.13 & 0.80 & $0.11 \frac{\bar{\sigma}}{0 .}$ \\
\hline Once a week & 17 & 0.17 & 0.48 & $0.12 \stackrel{\frac{\pi}{థ}}{\circ}$ \\
\hline$<$ once a week & 7 & -0.13 & 0.53 & $0.20 \stackrel{2}{\circ}$ \\
\hline
\end{tabular}

\section{Discussion}

The inhaled air in Kuwait contained crude oil and its breakdown products, mainly hydrocarbon vapoures hydrogen sulphite, carbon monoxide and trace metals including vanadium and nickel. This resulted in pollo tion similar in nature to that experienced in the Londôn smogs of the 1950s (2), in which the levels of sulph $\overrightarrow{u t}$ dioxide and smoke had the most immediate and obvious effect on health.

Measurement of individual exposure to polluted air Kuwait was difficult. Individual dosimeters are availabde but their use in the field would have been impractiol. Additionally the use of these might have hinderedot to subjects in what was already a difficult and dangero 6 job. Therefore it was decided simply to gain a fe $\overrightarrow{8}$ of exposure by questionnaire.

The majority of pollutants are attached to shy particles in the atmosphere including dust and sefo. These are monitored by the meteorology and Envinow mental Protection Agency (EPA) by measuring partions 10 microgrammes or below (PM10). The lowest level of PM10 documented by EPA in Kuwait is 340 microgrammes per $\mathrm{m}^{3}$ yet in May 1991, in Ras Tanajib gi Northern Saudi Arabia, near the border with Kuwait, was over 2500 microgrammes on certain days. Howevef, because the invasion halted most industrial activity and severely curtailed civilian car use, the level of PM10 i creased but the gaseous pollution did not.

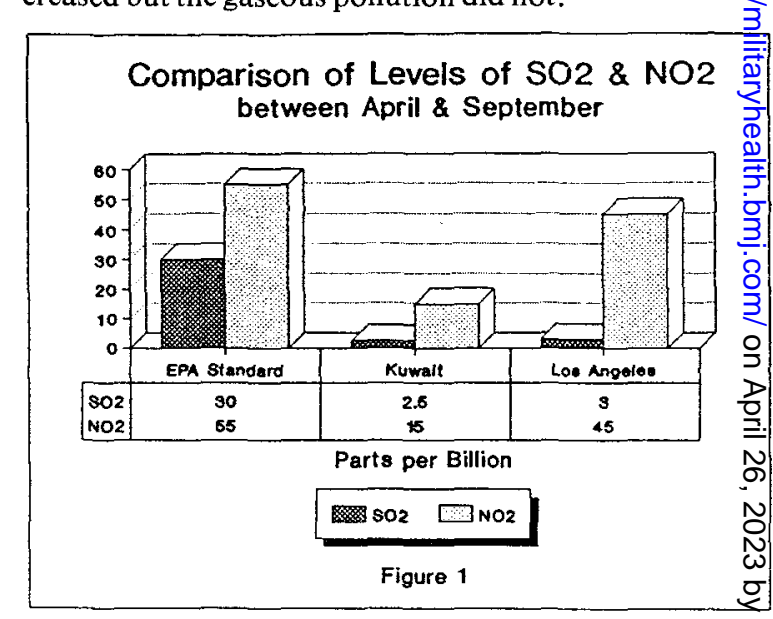




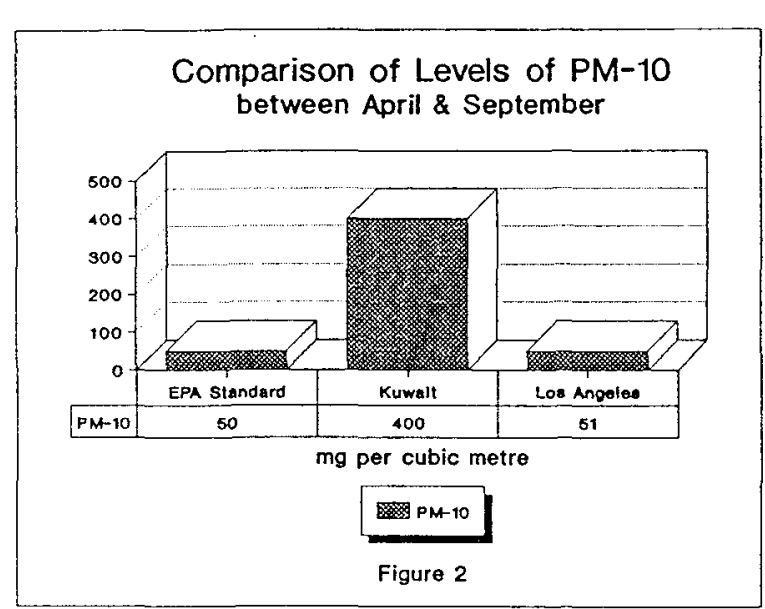

A comparison of average levels of sulphur dioxide, nitrous oxide and PM10 between April and September to those in Los Angeles in 1989 and to EPA standards are illustrated in Figure 1 and Figure 2 respectively. The apparent increase in pollution levels in Kuwait is not therefore supported by existing data. This may account for the absence of any recorded adverse effect.

However, it is accepted that all subjects were fit, healthy young men and one would not have expected to suffer significant short term effects.

Long term medical effects in soldiers exposed to the polluted air are possible but not predictable. A conservative estimate by Mohammid Sadiq (of King Fahd University of Petroleum and Minerals (KFUPM)) of vanadium and nickel inputs into the atmosphere were 3000 and 800 tonnes respectively up until 31st July 1991 .
Both trace metals have been linked to cancers of the res piratory tract and nasal cavities as indeed ar polyaromatic hydrocarbons. Arguably, the effects of cigarette smoking and normal environmental pollution could overshadow the effects of such pollution.

\section{Conclusion}

The importance of the study lies in the fact that it is to date the only study conducted in which objective mease urements of lung function were made before the subjects were exposed at all.

The choice of employing a vitalograph as the means of measurement was the best compromise between practI

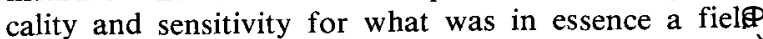
study; the measure used was a compromise betwee $\vec{\omega}$ pragmatism and scientific perfection.

\section{Acknowledgments}

Medical Section 21 EOD Royal Engineers for thei $\vec{E}$ help in data collection. Major R K G Dutton RA for hił help and advice in the final preparation and printing o屯 this article. Dr I M Kirk MB, CHB, MRCGP, for hie encouragement and advice in the Project as a whole.

\section{REFERENCES}

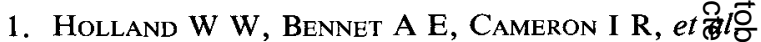
Health Effects of Particulate Pollution D Reappraising the Evidence. Am J Epidemiol 19更, 110 (5): 527-659.

2. Meetham A R, Bottom D W, Cayton Hedderson-Sellers A, Chambers D. Atmospherig Pollution, Its History, Origins and Prevention Pergammon Press, Oxford 1981. 